\title{
Suitability of passive integrated transponder tags and a new monitoring technique for at-risk madtoms (Noturus spp.)
}

\author{
David A. Schumann ${ }^{1,4,}{ }^{,}$, Michael E. Colvin ${ }^{1}$, Richard L. Campbell ${ }^{1}$, \\ Matthew D. Wagner ${ }^{2}$, Daniel E. Schwarz ${ }^{3}$ \\ ${ }^{1}$ Mississippi State University, Department of Wildlife, Fisheries, and Aquaculture, Mississippi State, MS 39762, USA \\ ${ }^{2}$ Mississippi Museum of Natural Science, Jackson, MS 39202, USA \\ ${ }^{3}$ United States Fish and Wildlife Service, Private John Allen National Fish Hatchery, Tupelo, MS 38804, USA \\ ${ }^{4}$ Present address: Department of Biology and River Studies Center, University of Wisconsin-La Crosse, La Crosse, WI 54601, USA
}

\begin{abstract}
Representative indices of population abundance for at-risk species are necessary to inform conservation decision-making. Many madtoms (Noturus spp.) are considered imperiled; however, the efficacy of frequent monitoring efforts has been questioned due to their cryptic and nocturnal behaviors. We systematically evaluated a madtom monitoring tool by (1) evaluating the use of small $(8 \times 2 \mathrm{~mm})$, surgically implanted $125 \mathrm{kHz}$ passive integrated transponder (PIT) tags for frecklebelly madtom $N$. munitus and (2) assessing the effectiveness of a radio-frequency identification (RFID)-enhanced artificial cover unit to index madtom abundance. Surgically implanted PIT tags had no apparent influence on madtom survival between 45 and $110 \mathrm{~mm}$ total length, and all tags were retained throughout a $21 \mathrm{~d}$ laboratory study. In experimental mesocosms, the enhanced cover units confirmed occupancy during nearly all replicates $(77.6 \%)$, even at extremely low densities ( $\mathrm{n}=2$ madtoms). The enhanced cover units provided representative estimates of madtom relative abundance $(p<0.01)$, whereas catch per unit effort was not significantly associated with previously validated visual observations $(p=0.12)$. Although madtom density and the number detected using the enhanced cover units were correlated, the gear was potentially saturated at relatively high densities ( 20 fish per mesocosm) when deploying a single unit. In most cases, occupancy was confirmed within $12 \mathrm{~h}$, and nearly half of the individuals were detected within $\sim 72 \mathrm{~h}$. Small PIT tags and RFID-enhanced artificial cover units offer novel opportunities to efficiently describe the ecology and population dynamics of madtoms.
\end{abstract}

KEY WORDS: Noturus - Frecklebelly madtom - Radio-frequency identification - RFID · Artificial cover units $\cdot$ Conservation $\cdot$ Passive integrated transponder tags

\section{INTRODUCTION}

Little ecological knowledge exists for many smallbodied, non-game fish despite these being disproportionately represented by species at risk of extinction (Burkhead 2012, Cooke et al. 2012). Rates of imperilment are particularly high for benthic species (e.g. sculpins, darters, and madtoms) that rely on vul-

${ }^{*}$ Corresponding author: dschumann@uwlax.edu nerable benthic habitats (Piller et al. 2004). Most madtoms (Ictaluridae: Noturus spp.), a monophyletic group of small catfish endemic to North America, are considered at risk of extinction by state or federal authorities (Bennett et al. 2008, Page et al. 2013). Although madtom species are difficult to detect due to their nocturnal behaviors and cryptic body patterns, frequent surveys are conducted to monitor 
their conservation status and inform management decisions (Peoples \& Frimpong 2011, Gibson-Reinemer et al. 2016, Reid \& Haxton 2017, Wagner et al. 2019).

Representative knowledge of fish distributional patterns and population structure are essential for effective conservation decision making (Smith et al. 2018). However, the effectiveness of traditional sampling efforts may poorly quantify status, occurrence, and population demographics for species that are difficult to detect (Hubert et al. 2012, Schloesser et al. 2012, Pregler et al. 2015), including madtoms (Midway et al. 2010a, Wagner et al. 2019). The development of standardized, species-specific sampling protocols has decreased concerns for many sportfish species (Neumann \& Allen 2007, Doyle et al. 2008); however, alternative sampling methods are not often available for small-bodied nongame fishes.

Madtoms readily use a variety of natural and artificial structures (Midway et al. 2010b, Slaughter 2020), a behavior exploited by previous researchers to describe occupancy, index population size, and monitor response patterns to habitat augmentation (Midway et al. 2010a, Cope et al. 2019). Artificial cover units attract individuals which can be visually inspected to inform occupancy analyses and to estimate relative abundance (Midway et al. 2010a, Cope et al. 2019). However, it is uncertain if the number of madtoms encountered at one time in a cover unit is related to local abundance. Refinements to this novel sampling method may facilitate the continuous detection of individually tagged madtoms without the need to disturb occupied habitats. The ability to detect tagged individuals would further benefit conservation efforts by providing opportunities to characterize lifehistory traits, estimate demographic rates and survival, and document behavior patterns (Ruetz et al. 2006, Cary et al. 2017). Additionally, detection of stocked individuals resulting from conservation culture can inform management action effectiveness.

Passive integrated transponder (PIT) tags were once too large for small-bodied individuals (Prentice et al. 1990, Gibbons \& Andrews 2004); however, advancements in tagging technology and associated surgical techniques now support diverse ecological inquiries of small fishes (Archdeacon et al. 2009, Kano et al. 2013, Tiffan et al. 2015, Pennock et al. 2016, Cary et al. 2017). The availability of smaller PIT tags may improve our understanding of small-bodied fish ecology, but their suitability has yet to be extensively tested for many taxonomic groups. Additionally, these tags offer little advantage for species that are difficult to detect or recapture following implantation. As a new method to index madtom abundance, we designed a radio-frequency identification (RFID)-enhanced artificial cover unit, capable of detecting PIT-tagged individuals as they enter and exit the unit.

Small PIT tags paired with artificial cover units may offer opportunities to improve our understanding of madtom ecology and evaluate the effectiveness of management actions, but the suitability of such tags has not been tested. Here we conducted 2 experiments to describe the feasibility of these methods for monitoring madtom populations. First, we conducted laboratory assessments of the response of frecklebelly madtom $N$. munitus, a candidate species for federal listing under the US Endangered Species Act, to surgically implanted PIT tags. We then quantified madtom use patterns and ability of RFIDenhanced artificial cover units to accurately index their abundance. In the second experiment, we monitored the use of cover units by madtoms to identify fish behaviors that may influence trap effectiveness (e.g. time to first detection) and evaluated the relationship between fish density and the number of unique madtom detections at varying population densities. Conclusions generated from this research support an innovative method to inform future reintroduction and monitoring efforts for this and related madtom species.

\section{MATERIALS AND METHODS}

\subsection{Study species}

The frecklebelly madtom is a small, non-game catfish that inhabits gravel shoals in large rivers and contributing tributaries in the southeastern USA (Shepard et al. 1997). This species can be locally abundant (Wagner et al. 2019), but declines have occurred throughout its native range (Shepard et al. 1997, Piller et al. 2004, Millican et al. 2006, Bennett et al. 2008). Although the frecklebelly madtom is now being considered for federal listing under the Endangered Species Act, the imperilment of this species has been recognized for more than a decade. Basic knowledge of its ecology and standardized assessments of its distribution and abundance are needed to inform impending conservation decisions.

\subsection{Species collection and acclimation}

Two independent experiments were conducted to evaluate the suitability of $8 \mathrm{~mm}$ PIT tags for freckle- 
belly madtoms and evaluate the ability of RFIDenhanced artificial cover units to monitor tagged individuals. An experimental pool of frecklebelly madtoms, from which study fish were randomly selected, was collected by backpack electrofishing into a $3.05 \mathrm{~m}$ seine from the Strong River (USGS hydrologic unit code [HUC10]: 0318000209), south-central Mississippi, USA. Captured fish were transported to the Private John Allen National Fish Hatchery research laboratory in $~ 501$ aerated containers, and care was taken to minimize handling stress (Harmon 2009). Fish were acclimated to laboratory conditions over a period of $21 \mathrm{~d}$ before any experimental procedures.

\subsection{Tagging technique}

No fish $<30 \mathrm{~mm}$ total length (TL) were tagged because earlier investigations showed low survival of smaller individuals of a closely related species (Schumann et al. 2020). Although not directly applicable to field studies, food was withheld for $36 \mathrm{~h}$ before PIT tag implantation to allow for consistent gut evacuation among individuals. All fish were removed from the housing tanks, anesthetized in tricaine methanesulfonate (MS-222, $100 \mathrm{mg} \mathrm{l}^{-1}$ ), and measured (to the nearest $1 \mathrm{~mm}$ ) before tag implantation. A 2-3 $\mathrm{mm}$ medial incision was made near the midventral line and anterior to the pelvic girdle using a $3.0 \mathrm{~mm}$ microsurgical scalpel (Prentice et al. 1990). A $125 \mathrm{kHz}$ PIT tag (EM4102 Injectable Transponder Animal Tags; $8.0 \times$ $2.0 \mathrm{~mm}, 0.06 \mathrm{~g}$, Eccei) was inserted into the peritoneal cavity with forceps and maneuvered into the abdominal cavity by hand (Knaepkens et al. 2007, Archdeacon et al. 2009). Surgical wounds were not closed using suture materials. All tags and surgical equipment were sanitized in $95 \%$ ethyl alcohol before each use to minimize infection (Dixon \& Mesa 2011). All tagged individuals were placed in aerated recovery tanks for 10 min post-surgery. Fish in the control treatment group were handled and anesthetized before being placed directly into the recovery tanks. During pilot investigations, respiration rate, movement behaviors, and righting response were visually approximated as normal within $10 \mathrm{~min}$. All fish were tagged using the same procedure in both experiments.

\subsection{Evaluating incision healing, survival, and PIT tag retention}

The suitability of surgically implanted PIT tags was evaluated by quantifying incision healing, tag reten- tion, and survival rates. We indiscriminately selected individuals from the acclimated source population and assigned each to either the control group $(n=36)$ or PIT-tagged treatment group $(\mathrm{n}=36)$. Fish assigned to the control group were anesthetized and immediately placed into treatment-specific recovery tanks, whereas the experimental group was subjected to the surgical treatment. Initial mortality was assigned to fish that died during the procedure or within the $10 \mathrm{~min}$ recovery period. Each treatment group was equally divided into 4 replicate tanks (38 1 capacity) within a shared 5601 water recirculating system ( $\mathrm{n}=9$ ind. $\operatorname{tank}^{-1}$ ). We monitored tank conditions and searched for mortalities and expelled PIT tags daily for $21 \mathrm{~d}$ following the procedure, which was considered an adequate amount of time to ensure that necessary healing and recovery occurred to sufficiently evaluate tag retention, survival, and incision healing (Kaemingk et al. 2011, Tiffan et al. 2015). We handled each individual on 3 weekly occasions to confirm tag retention and assess healing of the surgical incisions. Daily survival and PIT tag retention rates were expressed as the percentage of individuals within each replicate. Incision closure was visually documented using an index that was calibrated with histological evidence (Panther et al. 2011): 1, no evidence of a wound present and epidermal pigmentation appeared normal; 2, nearly completed healing, with minimal degree of fibrosis and/or mildly less than normal muscle density; 3, active but incomplete healing process with fusion but substantial fibrosis and/or inflammation; and 4, lack of normal tissue replacement in wound area (i.e. open wound). Weekly median healing values were used to characterize the differences in wound closure rates between treatment groups using Spearman rank-order correlation.

\subsection{Evaluating madtom abundance indices from tag detections and counts}

We modified the artificial cover units designed by Midway et al. (2010a) by installing an RFID antenna to the entrance to make an RFID-enhanced artificial cover unit (Fig. 1). A $125 \mathrm{kHz}$ circular antenna coil ( $51.5 \mathrm{~mm}$ diameter) was constructed using tightly wrapped 26-gauge magnet wire that was coated with a commercially available waterproof sealant (Flex Seal $^{\mathrm{TM}}$ ). The number of magnetic wire loops reflected inductance values between 1.3 and $1.4 \mathrm{mH}$, at which the RFID antenna performance was optimized. Sealed wire leads ran from the antenna to an Arduino circuit 


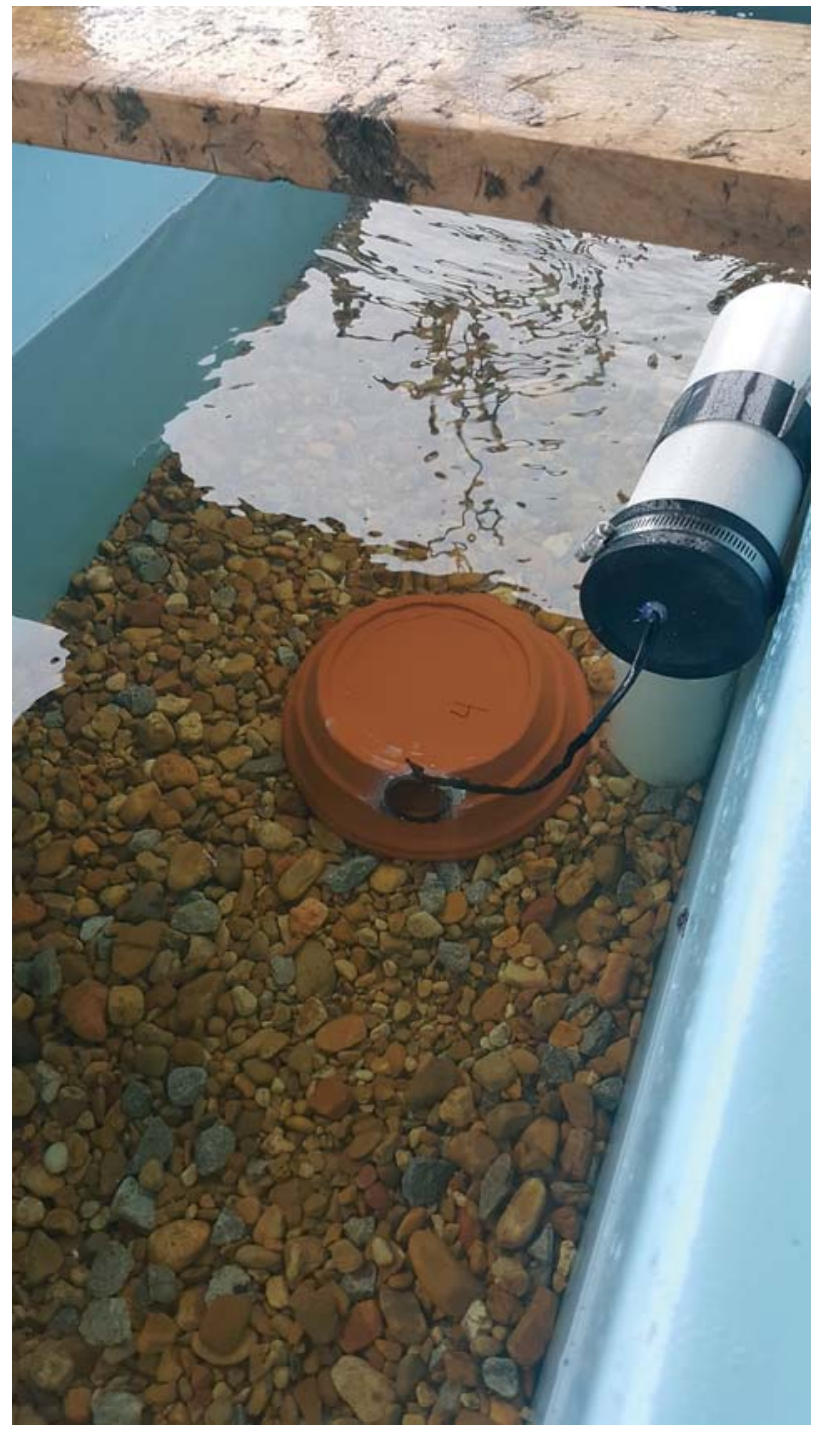

Fig. 1. Radio-frequency identification (RFID)-enhanced artificial cover unit (overturned terracotta saucer; round entrance opening is visible at the front) used to estimate the occurrence of passive integrated transponder (PIT)-tagged madtoms in an artificial mesocosm. The transmitter was powered by a portable battery unit

board specifically designed and programmed to record all PIT tag detections with a timestamp at $1 \mathrm{~s}$ intervals to a 32 GB SD (Secure Digital) card (Bridge et al. 2019). Arduino circuit boards are hobbyist electronics systems that are readily customized to accommodate diverse needs using available hardware and software (Bridge et al. 2019). The RFID reader was powered for $96 \mathrm{~h}$ using a portable battery pack (PowerCore II 20 000, 20100 mAh Portable Charger) via a micro-USB port (Fig. 1). The complete transmitter and battery supply were housed in a watertight PVC container and cost less than US \$100 (Fig. 1).
The effectiveness of these RFID-enhanced cover units depends on generating a suitable detection field for small PIT tags (Kano et al. 2013), madtom passing through the antenna array (i.e. using the units), and generating accurate relationships between population indices at varying madtom densities. The ability of the RFID-enhanced artificial cover units to index madtom density and the optimal sampling duration were evaluated by quantifying their use in $\sim 610 \mathrm{l}$ mesocosms. RFID-enhanced cover units were installed at the center of 4 replicate, flow-through mesocosms filled with gravel substrate. Individual madtom detections were monitored at 4 treatment densities: low ( $\mathrm{n}=2$ fish), moderate $(\mathrm{n}=10)$, high $(\mathrm{n}=20)$, and very high $(\mathrm{n}=30)$. The treatment densities were based on field observations of madtom populations in Mississippi (M. Wagner unpubl. data). This range of density treatments allowed us to evaluate the effectiveness of the cover units at varying fish densities and compare physical counts at the end of the trials to madtom abundance.

Tagged madtom detections were recorded for $96 \mathrm{~h}$ as individuals entered and exited the enhanced cover units during 8 replicated trials of the 4 madtom densities. All fish were selected from the experimental pool of tagged madtoms and randomly assigned to treatment groups with replacement, and density treatments were randomly assigned to mesocosms for each replicate.

\subsection{Data analysis}

\subsubsection{Incision healing, survival, and tag retention}

Failure-time analyses ('LIFETEST' procedure in SAS version 9.4) were conducted to test for differences among treatment-specific survivorship curves (Fox 2001). A Wilcoxon chi-squared test was used to compare cumulative mortality between treatment groups over the entire distribution of failure times (i.e. mortality at 0-21 d), rather than only on the final study day. This analysis manages right-censored data and does not assume the data are normally distributed (Fox 2001). All individuals that survived for $21 \mathrm{~d}$ were considered right-censored during this analysis. Significance was determined at $\alpha=0.05$. Additionally, logistic regression (SAS version 9.4) was used to assess the effect of initial TL on survival and tag retention of PIT-tagged individuals. The logistic response form was:

$$
Y_{i}=\mathrm{e}^{\left(\beta_{0}+\beta_{1} X_{i}\right)} /\left[1+\mathrm{e}^{\left(\beta_{0}+\beta_{1} X_{i}\right)}\right]
$$


where $Y_{i}$ is the survival or tag retention probability of fish $i$ on Day 21, $\beta_{0}$ is the regression intercept, $\beta_{1}$ is the regression slope, and $X_{i}$ is the TL of fish $i$.

\subsubsection{Indexing abundance with detections, use, and counts}

The number of madtoms observed using the RFID antennae and the traditional visual procedure were recorded at the end of each replicate (i.e. after $96 \mathrm{~h}$ ). The number of madtoms using the artificial cover units at the end of each trial was used to estimate the catch rates of a traditional visual procedure (Midway et al. 2010a, Cope et al. 2019). The relative accuracy of samples was assessed using linear regression to test how representative the collected samples were. Analysis of covariance (ANCOVA) was used to test for differences in the regression parameters (slope and intercept) as a result of the specific mesocosms and density treatments. If differences were observed in the number of detections among density treatment groups, we performed a Tukey-Kramer adjusted post hoc test to isolate the source of variation. For each analysis, significance was determined at $\alpha=0.05$.

Catch per unit effort (CPUE) was assumed to be proportional to treatment abundance and thus it was expected that the estimated occurrence of catches $>0$ and CPUE are related to the true abundance. We used logistic regression to relate the occurrence of one or more madtoms in a cover unit at the end of the trial with mesocosm abundance. We then evaluated the relationship of CPUE and mesocosm abundance as:

$$
\ln \left(\frac{C}{f}\right)=\beta_{0}+\beta_{1} \cdot \ln \left(\frac{N}{A}\right)
$$

where $C$ is the number of madtoms in the pot at the end of the trial, $f$ is the duration of the trial, $N$ is the madtom abundance in each mesocosm, $A$ is the area of each mesocosm, $\beta_{0}$ is the catchability when $\beta_{1}$ is 0 , and $\beta_{1}$ is the curvature between CPUE and madtom density. This equation was fit by ordinary least squares when CPUE was $>0$. Eq. (2) is a flexible extension of the catch effort equation $\frac{C}{f}=q \cdot N$ that allows for a potential non-linear relationship between CPUE and density resulting from hyperstability or hyperdepletion (Peterman \& Steer 1981, Harley et al. 2001, Walters 2003). The effect of density on detection (logistic model analysis) and CPUE (linear model analysis) was interpreted if the probability of the asymptotic chi-squared statistic based on the model deviance or the global $F$-statistic was $<0.05$.
To further describe the efficiency of the RFIDenhanced cover unit design, we assessed the individual use patterns of madtoms to approximate the ideal sampling duration. We recorded the time to first fish detection and the mean time to detection for all individuals for each density treatment. We developed product-limit survival curves to compare the rate at which unique madtoms were detected among treatment densities. A log-rank test was used to compare cumulative detection events among treatment densities over the entire distribution of times of first detection of an individual, rather than only at the end of the trial. If differences were observed among treatment groups, we performed a Šidák multiple comparison post hoc test to identify the source of variation (Fox 2001). Cumulative detection probabilities were estimated for each treatment to describe appropriate deployment periods.

\section{RESULTS}

\subsection{Incision healing, survival, and PIT tag retention}

Surgically implanted PIT tags had little apparent influence on madtom survival between 45 and $110 \mathrm{~mm}$ TL (Table 1). Nearly all of the tagged madtoms healed, survived, and retained PIT tags. Inflammatory responses were observed on the edges of the incision sites, but disappeared before $14 \mathrm{~d}$. Closure of the surgical wounds was nearly complete within $7 \mathrm{~d}$ of the procedure, and all wounds were completely healed within $3 \mathrm{wk}$ (Table 1). No mortality occurred during the procedure or recovery period for control

Table 1. Mean (SE) survival and tag retention of frecklebelly madtom Noturus munitus following the surgical implantation of passive integrated transponder (PIT) tags relative to control groups (handled only) after $21 \mathrm{~d}$. Median and range of values are provided for the wound healing index. There were no significant differences between treatments ( $\alpha=005)$. TL: total length

\begin{tabular}{|lcc|}
\hline & \multicolumn{2}{c|}{ Treatment } \\
\cline { 2 - 3 } Variable & Control & PIT \\
\hline Initial TL (mm) & $66.3(2.60)$ & $66.8(2.83)$ \\
Initial mortality (\%) & 0 & 0 \\
Survival to 21 d (\%) & $97.2(2.8)$ & $94.4(3.8)$ \\
Tag retention (\%) & No tag & $100(0.0)$ \\
Wound healing index & & \\
Day 7 & No tag & $2(1-3)$ \\
Day 14 & No tag & $1(1-3)$ \\
Day 21 & No tag & $1(1-1)$ \\
\hline
\end{tabular}


or PIT-tagged madtoms (Table 1). The proportion of individuals surviving the entire study period exceeded $90 \%$ (Fig. 2) and was statistically indistinguishable from controls $\left(\chi^{2}=0.31, \mathrm{df}=1, \mathrm{p}=0.57\right)$. TL at the time of tagging had little influence on madtom survival probability (logistic regression: intercept = 4.52, slope $=-0.026$ ). Madtom survival through $21 \mathrm{~d}$ is expected to exceed $90 \%$ for individuals $<95 \mathrm{~mm}$ (Fig. 3). Although the survival of larger individuals (i.e. up to $115 \mathrm{~mm}$ TL) was estimated to be lower (i.e. $\sim 82 \%$, Fig. 3), the response was influenced by the mortality of only 2 relatively large fish. No tags were ejected (Table 1).

\subsection{Evaluating detection, cover unit use, and population indices}

At least one madtom was detected during most trials using the PIT-tag enhanced cover units $(77.5 \%)$, whereas madtoms were visually observed using the cover units less than half of the time $(44.1 \%)$. Six failed deployments (i.e. 19.3\%) occurred when no madtoms used the cover units, most of which happened during the low density treatments (Table 2). The last failed deployment event was the result of user-error, i.e. a wire was

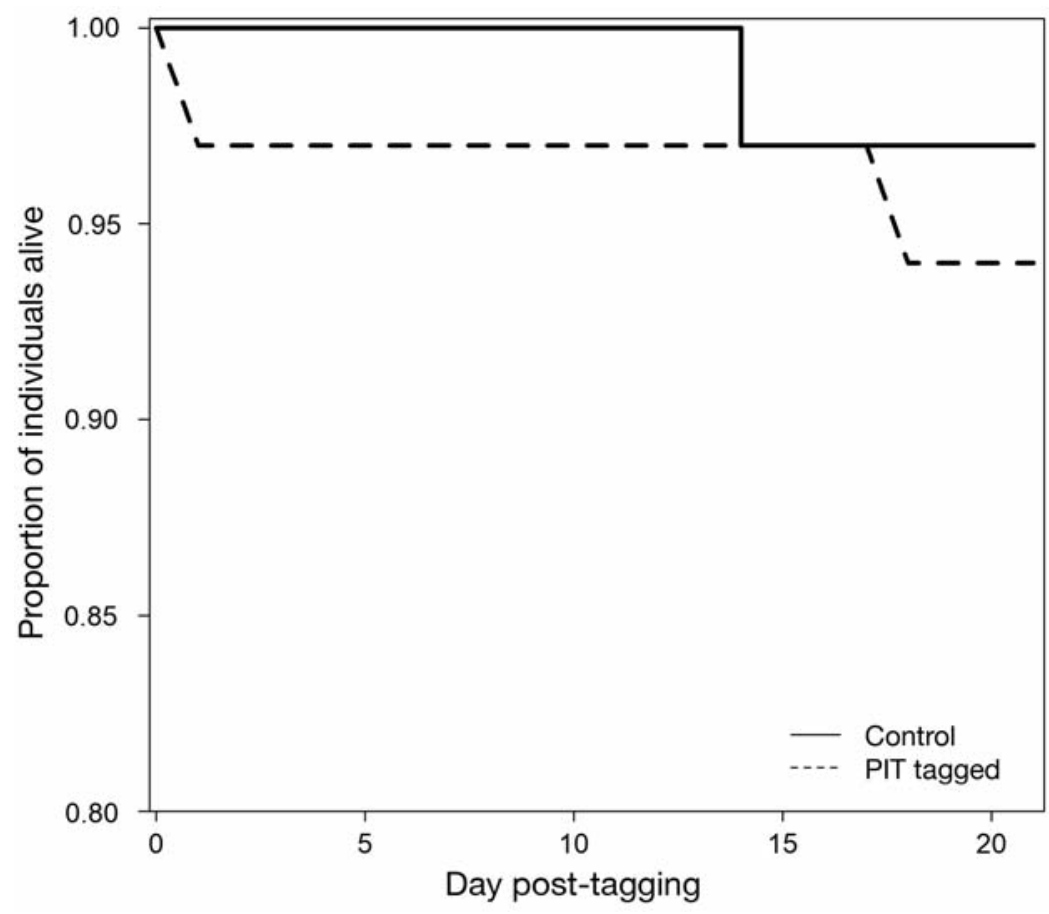

Fig. 2. Daily survival of frecklebelly madtoms Noturus munitus following the surgical implantation of passive integrated transponder tags over a $21 \mathrm{~d}$ trial period only partially connected, which caused it to disconnect mid-trial. On average, the proportion of individuals that were detected was higher when using the enhanced cover units $(0.35 \pm 0.06)$ than when individuals in the cover units were counted at the end (i.e. standard visual assessments, $0.08 \pm 0.03$ ). No deployments of the enhanced cover units were successful at detecting all tagged madtoms regardless of density (Table 2).

The number of tagged madtoms detected using the enhanced cover units was positively related to the true fish density in the mesocosms $\left(F_{1,29}=16.3, \mathrm{p}<\right.$ $\left.0.01, \mathrm{r}^{2}=0.36\right)$; however, CPUE was not significantly associated with mesocosm madtom density when physically observing individuals $\left(F_{1,16}=2.7, \mathrm{p}=0.12\right)$. The probability that a cover unit contained one or more madtoms at the end of the trial was not related to mesocosm density $\left(\chi_{38,39}^{2}=0.28, \mathrm{p}=0.59\right)$. The number of tagged individuals that were detected by the PIT-tag array was significantly different among treatment densities $(F=4.94, \mathrm{p}<0.01)$ when controlling for a mesocosm effect (Fig. 4). The gear was potentially saturated at relatively high densities, as we were unable to discern differences in the number detected when madtom were abundant (Table 2, Fig. 4). There was no significant difference in the relationship between true density and number detected as a function of the mesocosm used $(F=0.52, \mathrm{p}=0.67)$.

The rate at which tagged madtoms were detected and the total proportion that used the enhanced cover units varied by density level $\left(\chi^{2}=9.7\right.$, $\mathrm{df}=3$, $\mathrm{p}=0.02$; Fig. 5). Although madtoms were generally detected within $24 \mathrm{~h}$ when deployed to assess low-density populations $(n=2)$, in one extreme replicate, neither individual entered the cover unit for $>62 \mathrm{~h}$. The time to first madtom detection averaged $<12 \mathrm{~h}$ at all other densities (Table 2, Fig. 5). Although the mean time to detection was shortest at moderate densities, most madtoms that used the cover units made first contact within $\sim 30 \mathrm{~h}$ at all densities (Table 2). There were no significant differences in the amount of time required to describe madtom occurrence $\left(F_{3,19}=2.61, \mathrm{p}=0.08\right)$ nor the average time needed to detect madtoms that used the cover units $\left(F_{3}\right.$, $19=1.32, \mathrm{p}=0.30$ ) based on treatment density (Table 2). At all densities, 


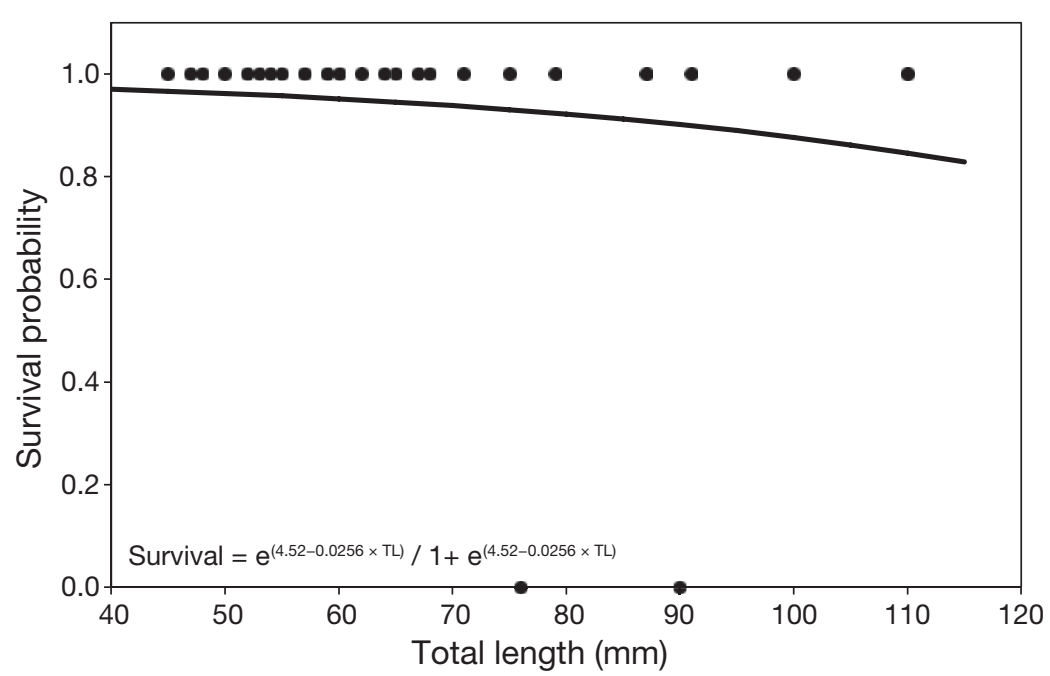

Fig. 3. Relationship between the initial total length (TL, $\mathrm{mm}$ ) of passive integrated transponder (PIT)-tagged frecklebelly madtoms Noturus munitus and their probability of survival to Day 21

except very high, half of the madtoms with access are expected to be detected within 72 h (Fig. 5), well within the expected battery life of the cover units.

\section{DISCUSSION}

Cryptic madtoms are difficult to detect during frequent survey attempts to monitor at-risk populations, which has hindered efforts to monitor conservation actions (Wagner et al. 2019). As a result, relatively little is known about the effectiveness of available conservation actions such as targeted reintroductions. Alternative methods to efficiently monitor madtom populations and generate novel ecological knowledge are needed to support the management of these vulnerable species. Surgically implanted PIT tags had little influence on the survival of frecklebelly madtoms that were $>45 \mathrm{~mm} \mathrm{TL}$, and no tags were ejected during the $21 \mathrm{~d}$ study period. Having observed almost no effect of the PIT tags on the fish, we moved forward to demonstrate the potential applications of this technology using RFID-enhanced artificial cover units (Midway et al. 2010a, Cope et al. 2019) .

Few studies have experimentally evaluated the suitability of small PIT tags for studies involving small-bodied catfishes (Musselman et al. 2017, Schumann et al. 2020), and to our knowledge, no research has evaluated their suitability for frecklebelly madtom or any other of the patterned madtoms (subgenus Rabida). Similar to other short-term tagging studies involving madtoms (Johnston \& Smithson 1999, Musselman et al. 2017, D'Amico 2018, Schumann et al. 2020), there was no apparent effect of the PIT tags on frecklebelly madtom survival. Retention of tags following their surgical implantation has been rarely reported to be below $90 \%$ for madtoms (but see Schumann et al. 2020), and zero ejections, as observed in the current study, have been reported for similarly sized madtoms (Musselman et al. 2017, D'Amico 2018). Surgically implanted tags are seemingly applicable to diverse studies of patterned madtoms, as researchers can rea-

Table 2. Mean (SE) number of tagged frecklebelly madtoms Noturus munitus detected at different densities using passive integrated transponder (PIT)-tag enhanced cover units and standard visual methods and mean time-to-detection data. Significantly different treatment effects at $\alpha=005$ are indicated by different superscript letters

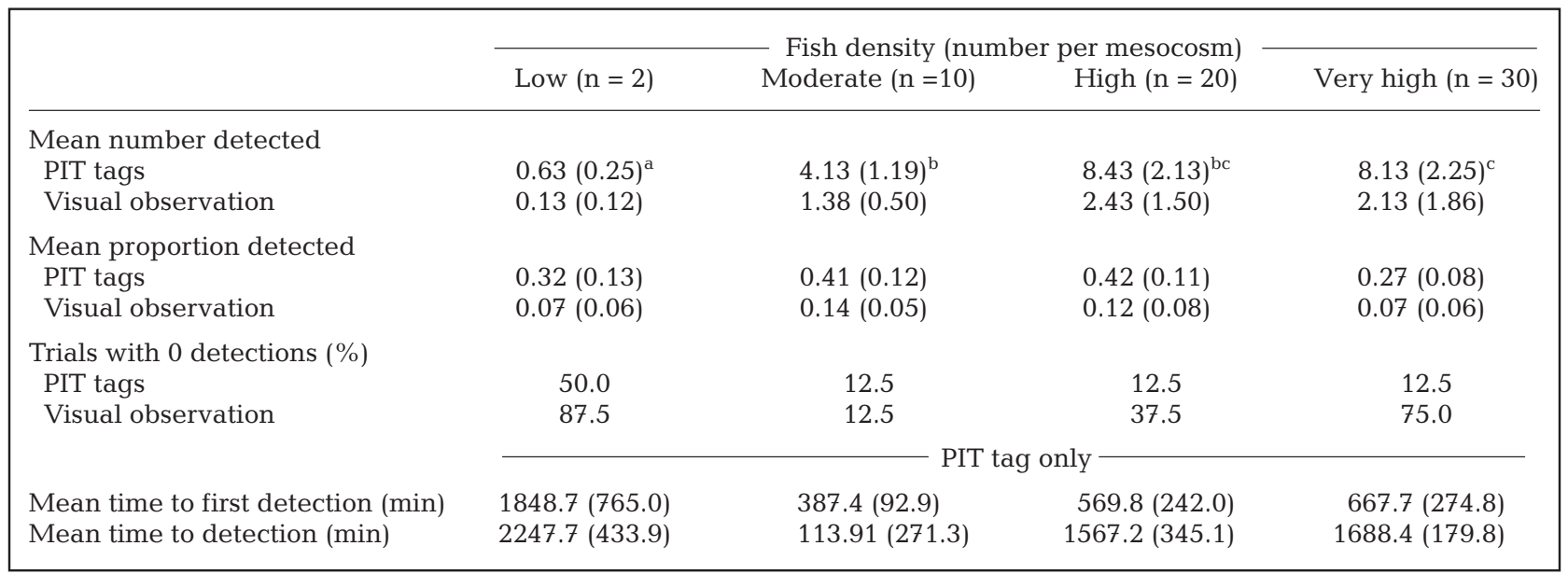




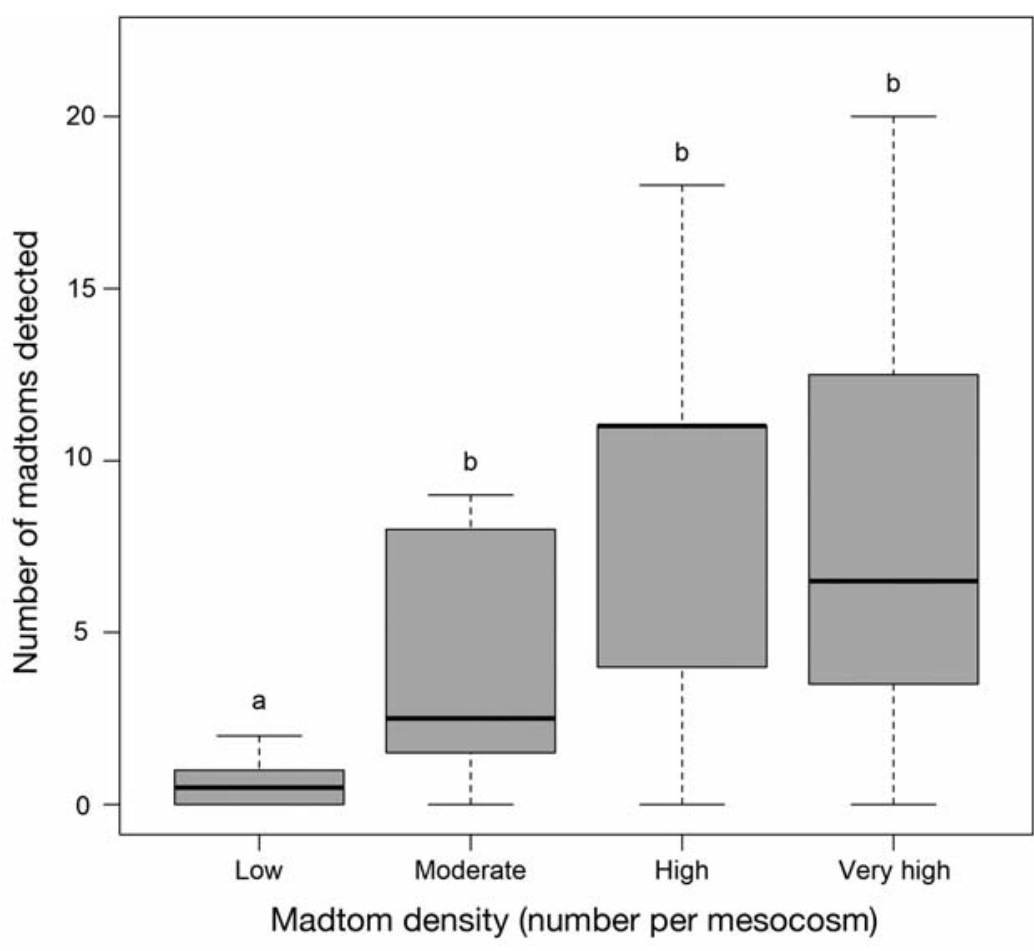

Fig. 4. Number of tagged madtoms detected using transmitter-enhanced artificial cover units by treatment density (low: $n=2$ fish, moderate: $n=10$, high: $\mathrm{n}=20$, and very high: $\mathrm{n}=30)$ during replicated $(\mathrm{N}=8)$ mesocosm trials. Bar: median; box: interquartile range; whiskers: minimum and maximum

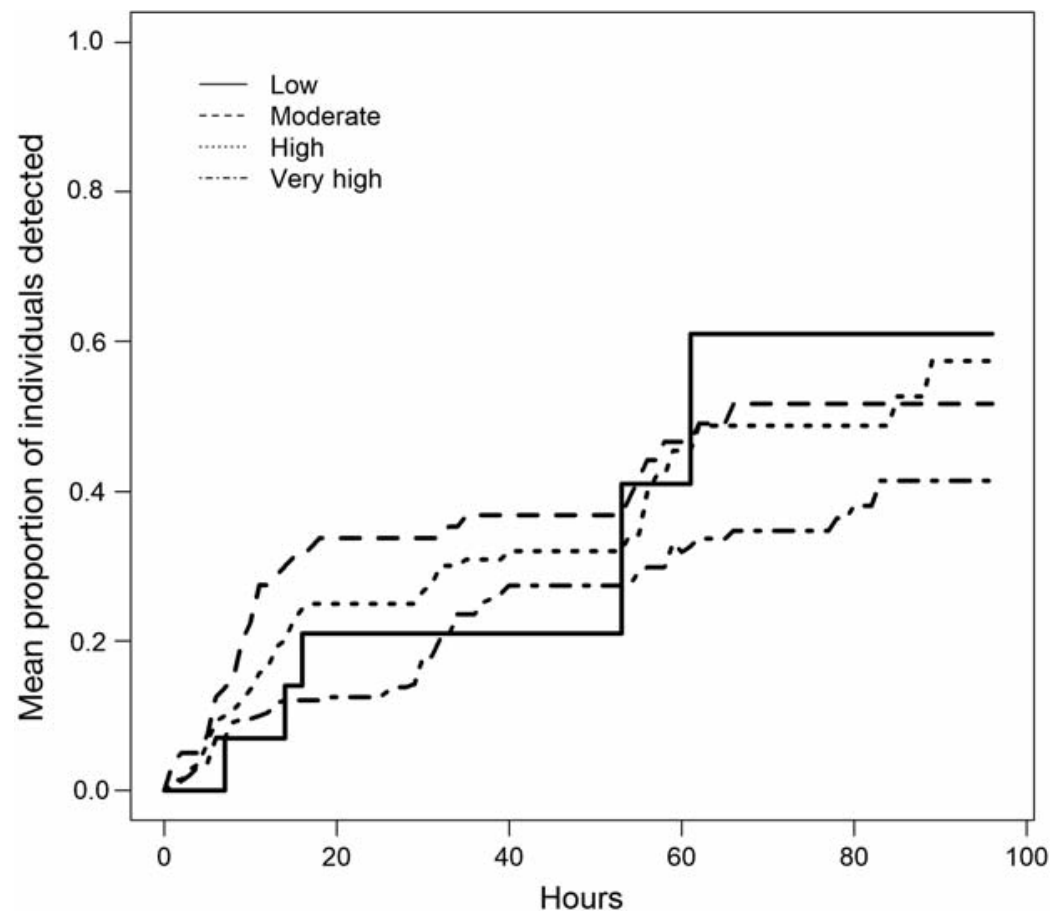

Fig. 5. Hourly depiction of the mean proportion of frecklebelly madtoms Noturus munitus detected using transmitter-enhanced artificial cover units during replicated $(\mathrm{N}=8)$ mesocosm trials. Treatment densities were as follows: low: $\mathrm{n}=2$ fish, moderate: $\mathrm{n}=10$, high: $\mathrm{n}=20$, and very high: $\mathrm{n}=30$ sonably expect rapid healing of the surgical wounds and minimal tag loss.

Because of widespread conservation concerns (Wagner et al. 2019), diverse madtom species are regularly targeted by surveys to inform management decisions. Previous efforts have demonstrated the effectiveness of artificial cover units as a method to passively describe madtom occurrence patterns and monitor populations relative to traditional sampling methods (Midway et al. 2010a,b, Cope et al. 2019). Our enhanced design builds upon these units by integrating a RFID transmitter that can record the entrance and exit times of individual madtoms and does not rely on continued use by fish to inform occupancy (Fig. 1). The enhanced cover units were able to confirm site occupancy within the mesocosms during almost all replicates $(\sim 78 \%)$, even at low fish densities. Although a previous study demonstrated high detection probabilities (0.92) for a closely related species, the Carolina madtom Noturus furiosus (Cope et al. 2019), visual observations alone would have failed to detect a madtom in more than half of the deployments during the current study, especially when madtoms occurred at low densities (i.e. $\mathrm{n}=2$ per mesocosm). Additionally, presence of one or more madtoms and the number captured in the RFID-enhanced cover units was not related to fish density using the standard visual method. Therefore, accurately assessing the occupancy state of a site needs to account for detection probability, as detecting madtoms using artificial cover units is imperfect. While evaluating behavior among individuals was beyond the scope of this study, known territoriality and the inconsistent temporal use of the enhanced cover units may explain this discrepancy in artificial cover unit use and density. The difficulty in detecting these relatively rare, cryptic fishes emphasizes the need for innovative sampling methods to inform management.

Although the number of tagged madtoms detected using the RFID-enhanced 
cover units was significantly related to fish density, the gear was potentially saturated at relatively high densities when deploying a single unit. We were generally unable to statistically describe differences in the number of fish detected when the abundance of madtoms in the mesocosms was high (i.e. $>20$ fish). Further investigations would better inform the number of units needed to develop truly representative abundance indices and describe the effective capture area of an individual cover unit. In most cases, the enhanced cover units were able to detect at least one tagged madtom in $<12 \mathrm{~h}$, suggesting that a single overnight set may reliably inform the occupancy state of a site. Furthermore, nearly $50 \%$ of the madtoms with access to the cover units first entered the units within $72 \mathrm{~h}$. Although it is unclear how these results will scale when applied to stream-reach level population inquiries, the standardized deployment of enhanced cover units could effectively monitor lowabundance madtom populations in shallow rivers.

Regular sampling is conducted to inform the management and evaluate the effectiveness of conservation actions for many imperiled madtoms; however, the usefulness of traditional gears is relatively poor (Piller et al. 2004, Wagner et al. 2019). The application of small PIT tag technology along with RFIDenhanced cover units not only provides robust estimates of population structure but may also address knowledge gaps in our understanding of madtom ecology. For example, we observed frecklebelly madtoms to routinely enter the sheltered cover units during the afternoon when air temperatures peaked, where they stayed until nightfall. As described by others (Midway et al. 2010a, Cope et al. 2019), the artificial cover units were also utilized by frecklebelly madtoms during spawning activities (D. Schwarz unpubl. data). The integration of an RFID antenna with already validated artificial cover units has enabled the efficient detection of unique individuals without the need to physically recapture fish or otherwise disturb the habitat. Although these cover units require little effort compared to active sampling methods (Cope et al. 2019), including portable PIT antennas (Cucherousset et al. 2005, 2010, Kelly et al. 2017), fish may be attracted to the units making them prone to potential bias. The units can be constructed in a matter of hours and quickly deployed by a single person and are relatively inexpensive (less than US \$100 per unit). Small PIT tags and RFID-enhanced artificial cover units offer novel opportunities to describe the ecology and population dynamics of patterned madtoms, and aquatic scientists now have critical information about their suitability.
Acknowledgements. This publication is a contribution of the Forest and Wildlife Research Center at Mississippi State University and was funded in part by Mississippi State University. We thank the US Fish and Wildlife Service, Private John Allen National Fish Hatchery, including Project Leader Richard Campbell and hatchery staff Lanna Bailey and Ronnie Schutkesting, for technical and data support. We thank Dr. Scott Rush for use of the Arduino boards used in this study. The findings and conclusions in this article are those of the authors and do not necessarily represent the views of the US Fish and Wildlife Service.

\section{LITERATURE CITED}

Archdeacon TP, Remshardt WJ, Knecht TL (2009) Comparison of two methods for implanting passive integrated transponders in Rio Grande silvery minnow. N Am J Fish Manag 29:346-351

Bennett MG, Kuhajda BR, Howell JH (2008) Status of the imperiled frecklebelly madtom, Noturus munitus (Siluriformes: Ictaluridae): a review of data from field surveys, museum records, and the literature. Southeast Nat 7 : 459-474

Bridge ES, Wilhelm J, Pandit MM, Moreno A and others (2019) An Arduino-based RFID platform for animal research. Front Ecol Environ 7:257

Burkhead NM (2012) Extinction rates in North American freshwater fishes, 1900-2010. Bioscience 62:798-808

Cary JB, Holbrook JL, Reed ME, Austin TB and others (2017) Survival of upper Piedmont stream fishes implanted with 8-mm passive integrated transponder tags. Trans Am Fish Soc 146:1223-1232

Cooke SJ, Paukert C, Hogan Z (2012) Endangered river fish: factors hindering conservation and restoration. Endang Species Res 17:179-191

Cope WR, Kwak TJ, Black TR, Pacifici K (2019) Evaluation of artificial cover units as a sampling technique and habitat enhancement for madtoms in rivers. N Am J Fish Manag 39:778-787

Cucherousset J, Roussel J, Keeler R, Cunjak RA, Stump R (2005) The use of two new portable 12-mm PIT tag detectors to track small fish in shallow streams. N Am J Fish Manag 25:270-274

* Cucherousset J, Britton JR, Beaumont WRC, Nyqvist M, Sievers K, Gozlan RE (2010) Determining the effects of species, environmental conditions and tracking method on the detection efficiency of portable PIT telemetry. J Fish Biol 76:1039-1045

D'Amico TW (2018) Stonecat ecology in St Vrain Creek. MSc thesis, Colorado State University, Fort Collins, CO

Dixon CJ, Mesa MG (2011) Survival and tag loss in Moapa White River springfish implanted with passive integrated transponder tags. Trans Am Fish Soc 140:1375-1379

Doyle W, Paukert C, Starostka A, Hill T (2008) A comparison of four types of sampling gear used to collect shovelnose sturgeon in the Lower Missouri River. J Appl Ichthyol 24: $637-642$

Fox GA (2001) Failure-time analysis: studying times to events and rates at which events occur. In: Scheiner SM, Gurevitch J (eds) Design and analysis of ecological experiments. Oxford University Press, New York, NY, p 235-266

Gibbons JW, Andrews KM (2004) PIT tagging: simple technology at its best. Bioscience 54:447-454

*Gibson-Reinemer DK, Stewart DR, Fritts MW, DeBoer JA, Casper AF (2016) Estimating the effects of environmental variables and gear type on the detection and occu- 
pancy of large-river fishes in a standardized sampling program using multiseason Bayesian mixture models. N Am J Fish Manag 36:1445-1456

Harley SJ, Myers RA, Dunn A (2001) Is catch-per-unit-effort proportional to abundance? Can J Fish Aquat Sci 58: 1760-1772

Harmon TS (2009) Methods for reducing stressors and maintaining water quality associated with live fish transport in tanks: a review of the basics. Rev Aquacult 1:58-66

Hubert WA, Pope KL, Dettmers JM (2012) Passive capture techniques. In: Zale AV, Parrish DA, Sutton TM (eds) Fisheries techniques, $3^{\text {rd }}$ edn. American Fisheries Society, Bethesda, MD, p 223-266

Johnston CE, Smithson EB (1999) Retention of passive integrated transponder (PIT) tags for individual identification of warmwater stream fishes. Southeastern Fishes Council Proceedings: No. 38

Kaemingk MA, Weber MJ, McKenna PR, Brown ML (2011) Effect of passive integrated transponder tag implantation of tag retention, growth and survival of two sizes of juvenile bluegills and yellow perch. N Am J Fish Manag 31: 726-732

Kano Y, Kawaguchi Y, Yamashita T, Sekijima T, Shimatani Y, Tangiuchi Y (2013) A passive integrated transponder tag implanted by a new alternative surgical method: effects on the oriental weather loach (Misgurnus anguillicaudatus) and application in a small irrigation system. Landsc Ecol Eng 9:281-287

Kelly BB, Cary JB, Smith AD, Pregler KC, Kim S, Kanno Y (2017) Detection efficiency of a portable PIT antenna for two small-bodied fishes in a Piedmont stream. N Am J Fish Manag 37:1362-1369

Knaepkens G, Maerten E, Tudorache C, De Boeck G, Eens M (2007) Evaluation of passive integrated transponder tags for marking bullhead (Cottus gobio), a small benthic freshwater fish: effects on survival, growth and swimming capacity. Ecol Freshw Fish 16:404-409

* Midway SR, Aday DD, Kwak TJ, Gross K (2010a) Cover preference of the Carolina madtom (Noturus furiosus), an imperiled, endemic southeastern stream fish. J Freshw Ecol 25:151-154

* Midway SR, Kwak TJ, Aday DD (2010b) Habitat suitability of the Carolina madtom, an imperiled, endemic stream fish. Trans Am Fish Soc 139:325-338

Millican DS, Roberts ME, Taylor CM (2006) Fish biodiversity in the Tombigbee River system after extensive ecosystem fragmentation. Tech Rep. Mississippi Museum of Natural Science, Jackson, MS

Musselman WC, Worthington TA, Mouser J, Williams DM, Brewer SK (2017) Passive integrated transponder tags: review of studies on warmwater fishes with notes on additional species. J Fish Wildl Manag 8:353-364

Neumann RM, Allen MS (2007) Size structure. In: Guy CS, Brown ML (eds) Analysis and interpretation of freshwater fisheries data. American Fisheries Society, Bethesda, MD, p 375-421

Page LM, Espinosa-Pérez H, Findley LT, Gilbert CR, Lea RN, Mandrak NE, Mayden RL (2013) New seventh edition of Common and Scientific Names of Fishes: Changes include capitalization of common names. Fish Mag 38: 188-189

Panther JL, Brown RS, Gaulke GL, Deters KA, Woodley CA, Eppard BM (2011) Influence of incision location on trans- mitter loss, healing, survival, growth and suture retention of juvenile Chinook salmon. Trans Am Fish Soc 140: 1492-1503

*Pennock CA, Frenette BD, Waters MJ, Gido KB (2016) Survival and tag retention of southern redbelly dace injected with two sizes of PIT tags. N Am J Fish Manag 36:1386-1394

Peoples BK, Frimpong EA (2011) Among-pass, interregional, and single- versus multiple-season comparisons of detection probabilities of stream fishes. Trans Am Fish Soc 140:67-83

*Peterman RM, Steer GJ (1981) Relation between sport-fishing catchability coefficients and salmon abundance. Trans Am Fish Soc 110:585-593

* Piller KR, Bart HL Jr, Tipton JA (2004) Decline of the frecklebelly madtom in the Pearl River based on contemporary and historical surveys. Trans Am Fish Soc 133: 1004-1013

Pregler KC, Vokoun JC, Jensen T, Hagstrom N (2015) Using multimethod occupancy estimation models to quantify gear differences in detection probabilities: Is backpack electrofishing missing occurrences for a species of concern? Trans Am Fish Soc 144:89-95

Prentice EF, Flagg TA, McCutcheon CS, Brastow DF, Cross DC (1990) Equipment, methods, and an automated dataentry station for PIT tagging. Am Fish Soc Symp 7: 335-340

* Reid SM, Haxton TJ (2017) Backpack electrofishing effort and imperfect detection: influence on riverine fish inventories and monitoring. J Appl Ichthyol 33:1083-1091

* Ruetz CR III, Earl BM, Kohler SL (2006) Evaluating passive integrated transponder tags for marking mottled sculpins: effects on growth and mortality. Trans Am Fish Soc 135:1456-1461

Schloesser JT, Paukert CP, Doyle WJ, Hill TD, Steffensen KD, Travnichek VH (2012) Heterogeneous detection probabilities for imperiled Missouri River fishes: implications for large-river monitoring programs. Endang Species Res 16:211-224

* Schumann DA, Graeb KN, Wagner MD, Graeb BDS, Prensosil E, Hoekwater J (2020) Suitability of surgically implanted 8-mm passive integrated transponder tags for small-bodied fishes. J Appl Ichthyol 36:682-692

Shepard TE, McGregor SW, O'Neil PE, Mettee MF (1997) Status survey of the frecklebelly madtom (Noturus munitus) in the Mobile River basin, 1995-1997. Geological Survey of Alabama, Tuscaloosa, AL

Slaughter M (2020) An investigation of cover preference of the mountain madtom (Noturus eleutherus). BSc thesis, Western Kentucky University, Bowling Green, KY

* Smith DR, Allan NL, McGowan CP, Szymanski JA, Oetker SR, Bell HM (2018) Development of a species status assessment process for decisions under the US Endangered Species Act. J Fish Wildl Manag 9:302-320

* Tiffan KF, Perry RW, Connor WP, Mullins FL, Rabe CD, Nelson DD (2015) Survival, growth, and tag retention in age0 chinook salmon implanted with 8-, 9-, and 12-mm PIT tags. N Am J Fish Manag 35:845-852

Wagner MD, Schumann DA, Smith BJ (2019) Gear effectiveness and size selectivity for five cryptic madtom species (Noturus spp.). J Appl Ichthyol 35:673-682

Walters C (2003) Folly and fantasy in the analysis of spatial catch rate data. Can J Fish Aquat Sci 60:1433-1436

Submitted: August 26, 2020; Accepted: October 19, 2020

Proofs received from author(s): December 17, 2020
Editorial responsibility: Eduardo Martins,

Vancouver, British Columbia, Canada 